\title{
Author Correction: A RAB35-p85/PI3K axis controls oscillatory apical protrusions required for efficient chemotactic migration
}

\author{
Salvatore Corallino ${ }^{1}$, Chiara Malinverno ${ }^{1}$, Beate Neumann ${ }^{2}$, Christian Tischer $^{2}$, Andrea Palamidessi ${ }^{1}$, \\ Emanuela Frittoli', Magdalini Panagiotakopoulou³, Andrea Disanza1, Gema Malet-Engra1, Paulina Nastaly ${ }^{1}$, \\ Camilla Galli ${ }^{1}$, Chiara Luise ${ }^{4}$, Giovanni Bertalot ${ }^{4}$, Salvatore Pece ${ }^{4}$, Pier Paolo Di Fiore (10 1,4,5, Nils Gauthier ${ }^{1}$, \\ Aldo Ferrari ${ }^{3}$, Paolo Maiuri (iD ${ }^{1}$ \& Giorgio Scita (10) ${ }^{1,5}$
}

Correction to: Nature Communications https://doi.org/10.1038/s41467-018-03571-8, published online 16 April 2018

The originally published version of this Article contained an error in the name of the author Salvatore Corallino, which was incorrectly given as Corallino Salvatore. This has now been corrected in both the PDF and HTML versions of the Article.

Published online: 22 May 2018

\begin{abstract}
(c) Open Access This article is licensed under a Creative Commons Attribution 4.0 International License, which permits use, sharing, adaptation, distribution and reproduction in any medium or format, as long as you give appropriate credit to the original author(s) and the source, provide a link to the Creative Commons license, and indicate if changes were made. The images or other third party material in this article are included in the article's Creative Commons license, unless indicated otherwise in a credit line to the material. If material is not included in the article's Creative Commons license and your intended use is not permitted by statutory regulation or exceeds the permitted use, you will need to obtain permission directly from the copyright holder. To view a copy of this license, visit http://creativecommons.org/licenses/by/4.0/.
\end{abstract}

(C) The Author(s) 2018

\footnotetext{
${ }^{1}$ IFOM, the FIRC Institute of Molecular Oncology, Via Adamello 16, 20139 Milan, Italy. ${ }^{2}$ Advanced Light Microscopy Facility, European Molecular Biology Laboratory, Meyerhofstr. 1, 69117 Heidelberg, Germany. ${ }^{3}$ ETH Zurich, Laboratory of Thermodynamics in Emerging Technologies, Sonneggstrasse 3,8092 Zurich, Switzerland. ${ }^{4}$ Department of Experimental Oncology, European Institute of Oncology, via Adamello 16, 20139 Milan, Italy. ${ }^{5}$ Department of Oncology and Hemato-Oncology, University of Milan, Via Festa del Perdono 7, 20122 Milan, Italy. Correspondence and requests for materials should be addressed to G.S. (email: Giorgio.scita@ifom.eu)
} 